\title{
Pengaruh Komitmen, Disiplin Kerja dan Kompetensi Terhadap Pelaksanaan K3
}

\section{Influence of Commitment, Work Discipline, and Competence on K3 Implementation}

\author{
Nana Putri Amelia ${ }^{1}$; Muhammad Ali Bin Syukur²; Dian Rachmawati Afandi ${ }^{3}$ \\ Falkutas Ilmu Ekonomi dan Bisnis Universitas Pelita Bangsa \\ nananana2882@gmail.com; andiali1280@gmail.com; dian.afandi@pelitabangsa.com
}

\begin{abstract}
Abstrak
Penelitian ini bertujuan untuk mengatahui pengaruh Komitmen karyawan, disiplin kerja dan kompetensi karyawan terhadap pelaksanaan K3. Populasi pada penelitian ini berjumlah 75 karyawan yang berkerja di berbagai perusahaan pada konstruksi Migas di kabupaten Tanjung Balai Karimun dengan menggunakan Sampel random Sampling. Teknis Analisis yang digunakan adalah mengunakan PLS dengan alat ukur skala linier. Hasil yang didapati pengaruh mengenai komitmen karyawan, disiplin kerja dan kompetensi karyawan terhadap pelaksanaan K3 memberikan pengaruh yang positif di perusahaan konstruksi Migas yang berada di Tanjung Balai Karimun.
\end{abstract}

'Kata Kunci: Komitmen, Disiplin, Kompetensi, Pelaksanaan K3

\section{Abstract}

This research aims to find out the influence of employee commitment, work discipline and employee competence on the implementation of K3. The population in this study amounted to 75 employees who worked in various companies in Oil and Gas construction in Tanjung Balai Karimun district using random sampling samples. Technical Analysis used is SmartPLS with linear scale measuring tool. The results found to affect employee commitment, work discipline and employee competence to the implementation of K3 have a positive influence on oil and gas construction companies located in Tanjung Balai Karimun.

Keyword: Komitmen Karyawan; Disiplin Kerja; Kompetensi Karyawan; pelaksanaan K3

\section{PENDAHULUAN}

Pertumbuhan dan penggunaan teknologi memasuki di era miliniar memiliki perkembang yang sangkat pesat, hal ini memberikan pengaruh pada keseluruhan lapisan kehidupan terutama di lapisan bisnis. Dengan persaingan yang samakin ketat dan kebutuhan manusia juga semakin meningkat salah satunya dalam segi kebutuhan layanan kesehatan, penggunaan mekanisasi, elektrisasi dan globalisasi memberikan dampak yang positif dan manfaat dalam pengadaannya namun juga memberikan dampak dan potensi yang berbahaya dalam penggunaannya.

Potensi bahaya sering dikarenakan oleh perilaku pekerja antara lain dikarenakan kelalaian atau kecerobohan. Dari data yang di peroleh pada tahun 2021 salah satu perusahan swasta yang bergerak 
dibidang konstruksi migas di kabupaten Tanjung Balai Karimun provinsi Kepuluan Riau, telah terjadi kecelakaan kerja yang mengakibatkan cacat di area jari tangan seorang pekerja subcontractor membuat perusahaan mengalami Lost Time Injury atau kehilangan jam kerja atas kelalaian dan kecerobohan dalam menjalankan pelaksanaan K3 selama proses pekerjaan berlangsung. Sehingga kelalaian dan kecerobahan pekerja menimbulkan permasalahan terhadap pelaksanaan K3. Hal ini didukung oleh hasil penelitian (Budiarti,2019), bahwa penyebab terbesar terhadap masalah kecelakaan kerja, berasal dari kecerobohan manusia dalam bekerja adalah $88 \%$, kemudian $10 \%$ akibat dari kualitas property/asset dll dan $2 \%$ dari factor lainnya (Mohd Adzim Khalili et al., 2013).

Pada penelitian sebelumnya (I Nyoman Dana, 2021) hasil penelitiannya menyebutkan "komitmen K3 tidak signifikan pengaruhnya terhadap perilaku pekerja. Sedangkan penelitian dari (Panca Adi Cahyono dan Rooslan Edi Santoso,2020) "adanya hubungan dan pengaruh yang signifikan antara sikap pekerja terhadap komitmen pekerja dilapangan yang terkait dengan penerapan program keselamatan dan kesehatan kerja. Pada hasil penelitian tersebut penulis memberikan hipotesis sementara bahwa adanya pengaruh baik besar ataupun kecil antara komitmen karyawan mengenai $\mathrm{K} 3$ terhadap perilaku karyawan sehingga memberikan pengaruh terhadap pelaksanaan K3.

Selain itu komitmen karyawan juga merupakan salah satu faktor yang menyebabkan terjadinya permasalahan terhadap pelaksanaan K3. Hal ini didukung oleh hasil penelitian (Monika indrayanti Sitanggang, 2019) "faktor penghambat dengan pelaksanaan SMK3 meliputi terdapat hubungan yang bermakna antara komitmen manajemen dan pekerja terhadap pelaksanaan SMK3."

Komitmen karyawan terhadap K3 menunjang pelaksanaan K3, komitmen seorang karyawan dapat menjadi lebih bertanggung jawab terhadap pekerjaannya dibanding dengan karyawan yang tidak mempunyai komitmen. Pernyataan ini di dukung oleh (Davis and Newstrom, 2002) yang menyatakan komitmen terhadap perusahaan adalah tingkat kemauan karyawan untuk mengindentifikasi dirinya pada perusahaan, dan keinginannya untuk melanjutkan partisipasi secara aktif dalam perusahaan tersebut. Hal tersebut menjadikan salah satu alasan perusahaan berupaya untuk meningkatkan komitmen karyawan untuk perusahaan agar dapat mengurangi potensi bahaya yang dapat ditimbulkan selama proses pekerjaan berlangsung.

Penulis mengembangkan hasil penelitian terdahulu, dimana penulis menambahkan disiplin kerja sebagai data intervening. Hal ini dikarenakan selain komitmen karyawan faktor yang mempengaruhi pelaksanaan $\mathrm{K} 3$ yakni faktor disiplin kerja (Flippo, 2004: 371). Selain itu faktor lainnya yang dapat mempengaruhi pelaksanaan $\mathrm{K} 3$ adalah Kompetensi. Jika seorang karyawan memiliki pengetahuan dan keterampilan dapat mempengaruhi pelaksanaan K3, pernyataan ini di dukung oleh hasil penelitian sebelumnya terdapat hubungan yang bermakna antara kualitas SDM terhadap pelaksanaan SMK3 (Monika indrayanti Sitanggang, 2019).

Untuk itu pada penelitian ini penting dilakukannya penelitian pengaruh komitmen karyawan, disiplin kerja serta kompetensi terhadap pelaksanaan K3. Tujuan dari penelitian ini secara umum adalah untuk mengetahui serta menganalisis pengaruh komitmen karyawan pada perusahan terhadap pelaksanaan K3 dilihat dari sudut disiplin kerja dan kompetensi karyawan dengan studi khasus di salah satu Perusahaan konstruksi migas yang berlokasi di Kabupaten Tanjung Balai Karimun Provinsi Kepuluan Riau yang bergerak pada sektor migas dan mengembangkan penelitian sebelumnya serta untuk memenuhi tugas ujian tegah semester 2 untuk program studi Master Management. 
Dimana pada penelitian ini diharapkan dapat memberikan manfaat serta kontribusi untuk penelitian selanjutnya.

\section{METODOLOGI PENELITIAN}

\section{Pengembangan Model}

\section{Pelaksanaan K3}

Berdasarkan undang- undang 50 Tahun 2012, pengertian keselamatan dan kesehatan kerja atau K3 adalah segala kegiatan untuk menjamin dan melindungi keselamatan dan kesehatan tenaga kerja melalui upaya pencegahan kecelakaan kerja dan penyakit akibat kerja.

Sebagaimana kita ketahui bahwa dalam suatu perusahaan memiliki organisasi secara menyeluruh diantaranya memiliki kegiatan perencanaan, pelaksanaan dan pengendalian terhadap segala kegiatan yang terjadi di dalam perusahaan. Untuk melaksanakaan pelaksanaan K3, setiap perusahaan memiliki standar yang di anut sesuai dengan kebutuhan perusahaan.

Pada perusahaan konstruksi migas yang ada di Tanjung Balai Karimun Kepulauan Riau, pelaksaanaan K3 di pantau dari evaluasi dan pengujian, Audit Sistem Manajemn K3 serta tindakan perbaikan dan pencegahan. Pengukuran pelaksanaan K3 yang dilakukan di sebuah perusahaan dapat dilihat melalui program K3 yakni, aturan kesehatan dan keselamatan, kesadaran atas aturan, pakaian pelindung, lantai bersih, cahaya di area produksi, lingkungan kerja, perlengkapan pemadam kebakaran, layanan pertolongan pertama dan medis, jumlah toilet mencukupi, kebersihan kamar mandi, program-program, tanda arah, air minum bersih, komite kesehatan dan keselamatan, prosedur kerja, prosedur kegawatan dan promosi kesehatan dan keselamatan (Makori, et.al, 2012, p.49).

Menurut International Association of Safety Professional, bahwa salah satu filosofi Pelaksaan K3 adalah Safety program must be site specific. Program K3 harus dibuat berdasarkan kebutuhan kondisi dan kebutuhan nyata di tempat kerja sesuai dengan potensi bahaya sifat kegiatan, Kultur, kemampuan finansial, dll. Program K3 dirancang spesifik untuk masingmasing organisasi atau perusahaan. (Dr. M. Bruri Triyono 2014).

\section{Komitmen Karyawan, Disiplin Kerja dan Pelaksanaan K3}

Dalam penelitian ini di ajukan beberapa hipotesis sebagai jawaban sementara diantara adanya hubungan antaranya adanya hubungan positif terhadap komitmen karyawan terhadap disiplin kerja, disiplin kerja terhadap pelaksanaan $\mathrm{K} 3$, serta komitmen karyawan terhadap pelaksanaan $\mathrm{K} 3$ melalui disiplin kerja dan kompetensi karyawan terhadap pelaksanaan K3. Penelitian ini akan menggunakan variable sebagai berikut

Komitmen pada organisasi didefenisikan sebagai suatu keadaan di mana seorang karyawan memihak pada suatu organisasi tertentu dan tujuantujuannya (Herman R.L.Siwy, 2017). Bentuk Komitmen karyawan terhadap perusahaan dapat dilihat kesungguhannya dalam mengekspresikan yang terbaik dari dirinya dan perannya dalam perusahaan tersebut serta berniat memelihara keanggotaan dalam organisasi. Kedisiplinan kerja salah satu bentuk wujud dari karyawan untuk mengekpresikan kesungguhan untuk mencapai tujuan karyawan tersebut untuk perusahaan. Semakin tinggi tingat komitmen seorang karyawaan maka tingkat disiplin kerja juga semakin tinggi.

Disiplin kerja bukti seorang karyawan patuh terhadap peraturan perusahaan, bertanggung jawab dengan pekerjaannya serta tertib terkait jam kerja perusahaan. Bila seorang pekerja telah patuh terhadap segala hal tersebut akan tinggi pengaruhnya terhadap pelaksaan kegiatan kerja nya termasuk pelaksanaan K3. Hal ini dikarenakan setiap kegiatan kerja memiliki tahapan terhadap kepatuhan peraturan K3 yang harus di jalankan. 
Karyawan yang memiliki komitmen yang tinggi terhadap perusahaan pasti mematuhi segala aturan serta bertanggung jawab atas pekerjaan yang ditentukan. Bentuk karyawan yang patuh terhadap peraturan dan bertanggung jawab akan pekerjaan tersebut yakni karyawan yang memiliki disiplin kerja yang baik. Dengan disiplin kerja yang baik akan menghasilkan kinerja yang baik pula termasuk kinerja terkait K3 dengan begitu untuk menghasilkan kinerja K3 yang baik pastinya karyawan akan melaksanakan K3 dengan baik sesuai aturan yang telah diterapkan oleh perusahaan.

Menurut Ardana (2012: 134) disiplin kerja diartikan sebagai suatu sikap menghormati, menghargai, patuh, dan taat terhadap peraturan-peraturan yang berlaku baik yang tertulis maupun tidak tertulis serta sanggup menjalankannya dan tidak mengelak untuk menerima sanksisanksinya.

H1. Ada pengaruh komitmen karyawan terhadap disiplin

H2. Ada pengaruh disiplin kerja terhadap Pelaksanaan K3

H3.Adanya pengaruh komitmen Karyawan terhadap pelaksanaan K3 melalui Disiplin Kerja

\section{Kompetensi dan Pelaksanaan K3}

Winarno dan Perdana menyatakan bahwa kompetensi adalah sebagai karakteristik individu yang dapat diukur dan ditentukan untuk menunjukkan perilaku dan kinerja tertentu pada seseorang. Dwomoh (2013) dalam sebuah laporan yang diterbitkan pada tahun 2001 oleh Komisi Kesehatan dan Keselamatan Inggris (HSC) dan Eksekutif Kesehatan dan Keselamatan Kerja (HSE), ketika karyawan dievaluasi untuk kinerja keselamatan mereka, hal ini termasuk untuk menerapkan gagasan peningkatan keselamatan dan kesehatan kerja karyawan

Menurut Kaynak et al (2016), keselamatan dan kesehatan kerja karyawan merupakan bagian dari kerangka kerja manajemen keselamatan dan kesehatan yang efisien. Hal tersebut menunjukkan kesediaan manajemen untuk menyediakan pekerja dengan tempat kerja yang sehat dan aman.

Diduga ketika karyawan memiliki kompetensi yang baik akan memberikan pengaruh yang signifikan terhadap pelaksanaan K3 dimana pelaksanaan K3 yang baik merupakan bagaian dari hasil kinerja karyawan yang baik pula.

H4. Diduga adanya pengaruh kompetensin karyawan terhadap Pelaksanaan K3

\section{Pengumpulan Data}

Penelitian akan dilakukan diperusahaan salah satu perusahan yang bergerak di bidang konstruksi migas yang berada di Kabupaten Tanjung Balai Karimun provinsi Kepulauan riau. Dengan teknik pengambilan data menggunakan Sempel Acak Sederhana (Sample Random Sampling). Sempel Acak Sederhana adalah teknik pengambilan sampel dari anggota populasi yang dilakukan secara acak tanpa memperhatikan strata yang ada dalam populasi itu. (Sugiyono, 2001:57). Dimana peneliti mengambil sampel 75 karyawan dari berbagai perusahaan baik Karyawan dengan status permanen maupun PKWT. Data dikumpulkan menggunakan kuesioner. (Sugiyono, 2017:194). Dimana peneliti akan menyebarkan lembar kuisioner kepada seluruh karyawan melalui google form dengan waktu 3 hari kerja, hingga terkumpul 75 sampel tercepat yang telah mengisi dan mengirim kembali lembar form kuisioner tersebut.

\section{Metode Analisis}

Peneliti akan menggunakan metode kuantitatif (Creswell 2012:13). Jenis analisis yang akan kita gunakan ialah menggunakan teknis analisis berbasis PLS (Partial Least Square) dengan menggunakan aplikasi Smart PLS versi 3.0. Pengukuran model PLS yang harus di adalah outer model pengujian menggunakan loading outer untuk mengukur validitas. Besaran nilai minimal ialah $>0,7$ tetapi masih tetap 
dipertahankan jika nilai loadings outer tidak kurang dari 0,4. Melakukan pengujian pada Rata-Rata Varian diestrak (AVE) dengan cut off $>0.5$ untuk menentukan Realibilitas. Selain Cronbach's Alpha dengan cut off $>0,7$ dan digunakan juga nilai $\rho c$ (composite reliability) yang diinterpretasikan dengan nilai Cronbach's Alpha dengan cut off $>0,8$. Indikator model NFI $>0,1$ serta nilai Pengujian hubungan jalur dalam model structural menggunakan standar estimasi dengan cut off $\mathrm{p}$-value $<0,05$.

\section{Desain Penelitian}

Dari gambar 1 dapat di jelaskan pengaruhi Komitmen terhadap disiplin kerja, pengaruh Disiplin terhadap pelaksanaan K3, pengaruh komitmen dan disiplin kerja terhadap pelaksanaan $\mathrm{K} 3$ serta pengaruh kompetensi karyawan terhadap pelaksanaan K3. Untuk mengukur pengaruh tersebut peneliti menggunakan indikator sebagaimana yang terlampir pada tabel 1 Operasional Variabel.

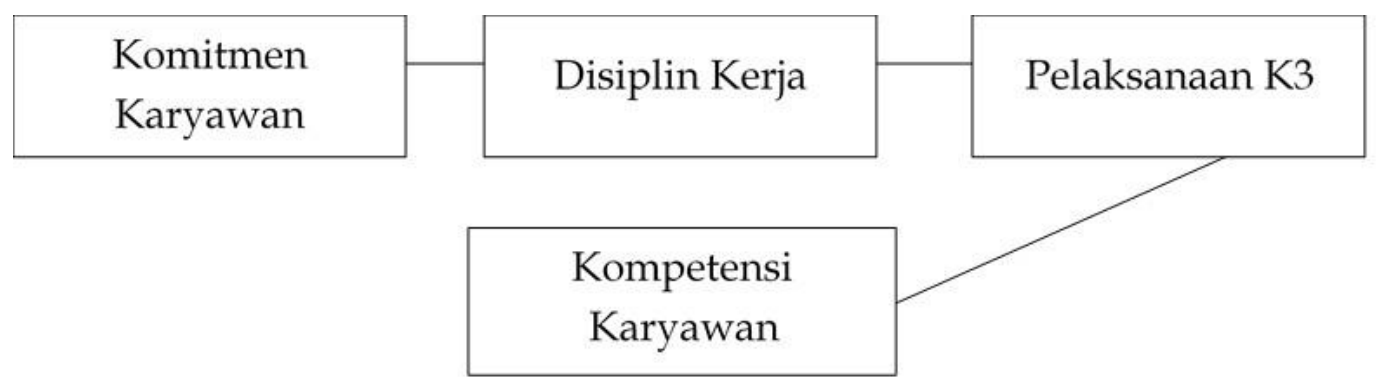

Gambar 1. Desain Penelitian

Tabel 1. Operasionalisasi Variabel

\begin{tabular}{lllc}
\hline \multicolumn{1}{c}{ Variabel } & \multicolumn{1}{c}{ Indikator } & Skala \\
\hline Komitmen Karyawan & 1. Penerimaan nilai organisasi dalam K3 & $1-10$ \\
(Mauday el al,1983) & 2. Keinginan kuat mendukung organisasi dalam K3 & \\
& 3. Penerimaan tujuan organisasi dalam K3 & $1-10$ \\
\hline Disiplin Kerja & 1. Ketepatan waktu datang ke meeting K3 tempat kerja & \\
(Hasibuan (2014:190)) & 2. Kepatuhan terhadap peraturan K3 yang berlaku. & \\
& 3. Penggunaan APD (Alat Pelindung Diri) & \\
& 4. Tanggung jawab K3 dalam mengerjakan tugas. & \\
\hline Kompetensi (Ruky & 1. Karakter pribadi (traits) & \\
dalam Fadillah & 2. Konsep diri (self concept) & \\
dkk,2017) & 3. Pengetahuan (knowledge) & \\
& 4. Keterampilan (skill) & \\
\hline Kesehatan dan & 5. Motivasi kerja (motives) & \\
keselamatan Kerja & 1. Keadaan dan kondisi karyawan & \\
(Manullang(2000: 87; & 2. Lingkungan kerja & \\
Sama'mur (2005:7) $)$ & 4. Kerlindungan Karyawan & \\
& 5. Pengaturan udara & \\
& 6. Pengaturan penerangan & \\
& 7. Pemakaian peralatan kerja & \\
& 8. Kondisi fisik dan mental pegawai &
\end{tabular}




\section{HASIL PENELITIAN}

Dari tabel 2 hasil demografi gender dapat dijelaskan reponden laki-laki lebih dominan berkerja diperindustian konstruksi Migas dengan perolehan responden sebesar 93\% dibandingkan responden wanita sebanyak 7\% di wilayah Tanjung Balai Karimun.

Tabel 2. Hasil Demografi Gender

\begin{tabular}{lcc}
\hline \multicolumn{1}{c}{ Gender } & Frekuensi & Percent \\
\hline Laki-Laki & 70 & $93 \%$ \\
Perempuan & 5 & $7 \%$ \\
Total & 75 & $100 \%$ \\
\hline
\end{tabular}

Sumber: Data Primer yang diperoleh, 2021

Tabel 3. Hasil Uji Outer Model

\begin{tabular}{|c|c|c|c|c|c|}
\hline \multirow{2}{*}{ Variabel Indikator } & \multirow{2}{*}{$\begin{array}{l}\text { Outer } \\
\text { Loading }\end{array}$} & \multicolumn{2}{|c|}{ Crombah Composite } & \multirow{2}{*}{ AVE } & \multirow{2}{*}{ Kesimpulan } \\
\hline & & Alpha & Reability & & \\
\hline Disiplin Kerja (A) & & 0.786 & 0.861 & 0.609 & Reliabel \\
\hline$\circ$ Taat mengikuti meeting pengarahan K3. & 0.759 & & & & Valid \\
\hline ○ Mengikuti aturan K3 perusahaan. & 0.806 & & & & Valid \\
\hline ○ Patuh menggunakan APD & 0.811 & & & & Valid \\
\hline - Bertanggug jawab mengikuti aturan $\mathrm{K} 3$ & 0.744 & & & & Valid \\
\hline Komitmen Karyawan (B) & & 0.767 & 0.857 & 0.668 & Reliabel \\
\hline ○ Memiliki keinginan kuat menerapkan K3 & 0.847 & & & & Valid \\
\hline ○ Mendukung budaya K3 di perusahaan & 0.867 & & & & Valid \\
\hline $\begin{array}{l}\text { - Berusaha seoptimal mungkin mendukung } \\
\text { tujuan bebas kecelakaan kerja }\end{array}$ & 0.732 & & & & Valid \\
\hline Kompetensi Karyawan $(\mathrm{C})$ & & 0.707 & 0.819 & 0.531 & Reliabel \\
\hline - Memahami aturan dan norma K3 & 0.747 & & & & Valid \\
\hline o Memiliki prinsip diri melaksakan K3 & 0.757 & & & & Valid \\
\hline - Memiliki pengetahuan prosedure kemanan & 0.672 & & & & Valid \\
\hline o Tergerak melatih kemampuan K3 & 0.737 & & & & Valid \\
\hline Pelaksanaan K3 & & 0.807 & 0.861 & 0.509 & Reliabel \\
\hline ○ Bekerja ketika jika benar-benar sehat & 0.676 & & & & Valid \\
\hline $\begin{array}{l}\text { - Bekerja ketika lingkungan kerja dipastikan } \\
\text { tidak mengganggu kesehatan }\end{array}$ & 0.769 & & & & Valid \\
\hline $\begin{array}{l}\text { - Bekerja ketika ada kepastian perlindungan } \\
\text { kesehatan }\end{array}$ & 0.694 & & & & Valid \\
\hline $\begin{array}{l}\text { - Memastikan lingkungan kerja aman untuk } \\
\text { melaksanakan tugas }\end{array}$ & 0.729 & & & & Valid \\
\hline $\begin{array}{l}\text { Melakukan pengecekan untuk memastikan } \\
\text { suhu udara normal }\end{array}$ & 0.704 & & & & Valid \\
\hline $\begin{array}{l}\text { Bekerja ketika tidak mengalami gangguan } \\
\text { fisik dan metal }\end{array}$ & 0.705 & & & & Valid \\
\hline
\end{tabular}

Sumber: Data Primer yang diolah, 2021

Tabel 3 dihapus beberapa indikator yang hasilnya tidak valid pada variabel kompetensi karyawan yakni indikator keterampilan serta pada variabel pelaksanaan $\mathrm{K} 3$ dengan indikator pengatur penerangan dan pemakaian peralatan kerja sehingga memperoleh data pada tabel 2 hasil uji Outer Model yang di nilai telah valid dan reliabel (Crombah Alpha Disiplin Kerja 0.786; Komitmen Karyawan 0.767; 
Kompetensi Karyawan 0.707 dan Pelaksanaan K3 0.807 lebih besar dari 0.7. sedanglan Composite Reliability Disiplin Kerja 0.861; Komitmen Karyawan 0.857; Kompetensi Karyawan 0.819 dan Pelaksanaan K3 0.861 lebih besar dari 0.8 Pada tabel hasi uji Outer Model peroleh nilai Outer loading di $<0.6$ peneliti tetap mempertahankannya karna nilai pada AVE telah terpenuhi (Rata-Rata Varian diestrak AVE Disiplin Kerja 0.609; Komitmen Karyawan 0.668; Kompetensi Karyawan 0.531 dan Pelaksanaan K3 0.509 lebih besar dari 0.5).

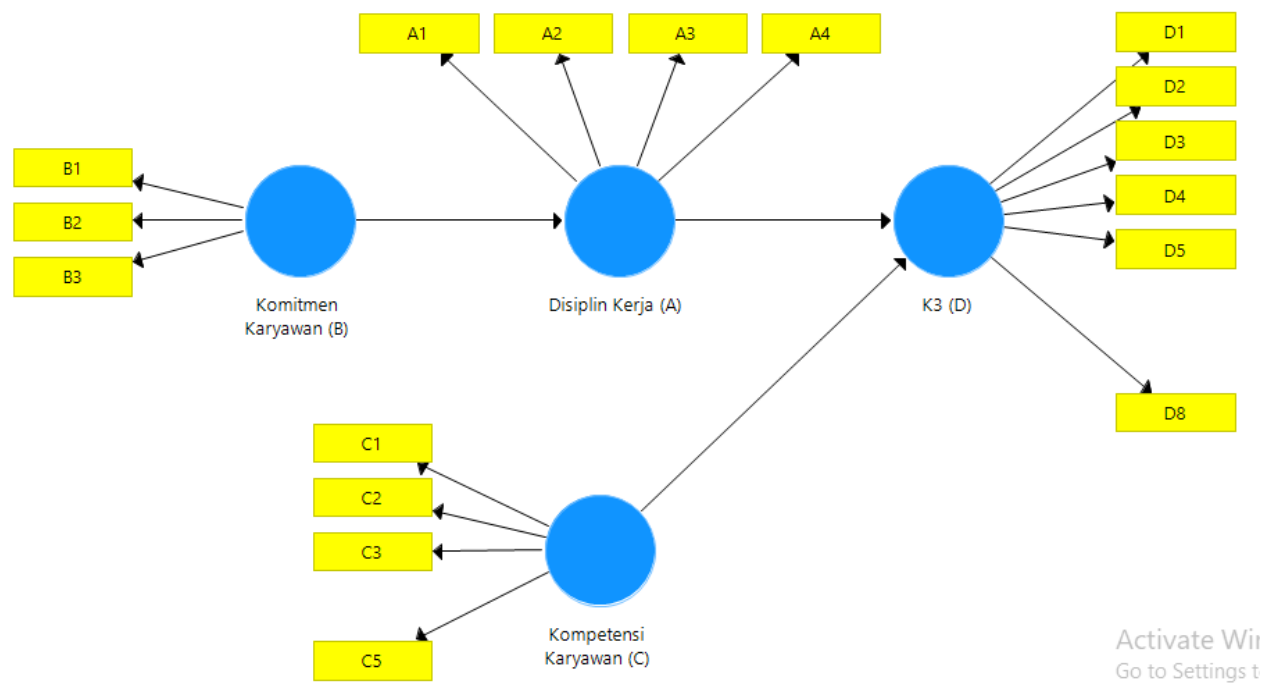

Gambar 2. Outer Model Lengkap

Tabel 4. Uji Model NFI

\begin{tabular}{lcc}
\hline & Model Saturated & Model Estimasi \\
\hline SRMR & 0.099 & 0.104 \\
d_ULS & 1.485 & 1.647 \\
d_G & 0.628 & 0.654 \\
Chi-squre & 244.152 & 248.478 \\
NFI & 0.595 & 0.588 \\
\hline
\end{tabular}

Sumber: Data Primer yang diolah, 2021

Tabel 5. Indeks Pengujian Model

\begin{tabular}{llll}
\hline Endogenous Variabel & $\begin{array}{l}\text { Cut of } \\
\text { Value }\end{array}$ & $\begin{array}{l}\text { Hasil } \\
\text { Analisis }\end{array}$ & Evaluasi model \\
\hline R2 & & & \\
- Disiplin Kerja & $\geq 0,2$ & 0,2 & Fit \\
- Pelaksanaan K3 & $\geq 0,2$ & 0,6 & Fit
\end{tabular}

Sumber: Data Primer yang diolah, 2021 
Tabel 6. Estimasi

\begin{tabular}{|c|c|c|c|c|c|}
\hline Alur & Jenis & $\begin{array}{l}\text { Original } \\
\text { Sample }\end{array}$ & T Statistic & P Value & Kesimpulan \\
\hline $\begin{array}{l}\text { Disiplin kerja -> } \\
\text { Pelaksanaan K3 }\end{array}$ & Langsung & 0.503 & 6.439 & 0.000 & Signifikan \\
\hline $\begin{array}{l}\text { Komitmen Karyawan -> } \\
\text { Disiplin Kerja }\end{array}$ & Langsung & 0.453 & 5.968 & 0.000 & Signifikan \\
\hline $\begin{array}{l}\text { Kompetensi -> Pelaksanaan } \\
\text { K3 }\end{array}$ & Langsung & 0.368 & 3.921 & 0.000 & Signifikan \\
\hline $\begin{array}{l}\text { Komitmen karyawan -> } \\
\text { Pelaksanaan K3 }\end{array}$ & $\begin{array}{c}\text { Tidak } \\
\text { Langsung }\end{array}$ & 0.167 & 2.847 & 0.005 & Signifikan \\
\hline $\begin{array}{l}\text { Komitmen karyawan -> } \\
\text { Disiplin Kerja -> } \\
\text { Pelaksanaan K3 }\end{array}$ & $\begin{array}{l}\text { Tidak } \\
\text { Langsung }\end{array}$ & 0.167 & 2.871 & 0.004 & Signifikan \\
\hline
\end{tabular}

Sumber: Data penelitian yang diolah, 2021

Tabel 4 menunjukan hasil analisis NFI sebesar 0,6 degan cut off nilai NFI $>0,1$ maka model dapat dikatakan jauh lebih baik. Sedangkan tabel indeks pengujian model evaluasi model dinyatakan fit dengan hasil analisis pengujian memperoleh 0.181 dimana bila di bulatkan menjadi 0.2 pada disiplin kerja serta 0,6 pada pelaksanaan $\mathrm{K} 3$ yang mana telah memenuhi cut off $\geq 0.2$.

Tabel 6 memperlihatkan pengaruh variabel bahwa : 1) Disiplin kerja terhadap pelaksanaan K3 memiliki pengaruh positif; 2) Komitmen Karyawan terhadap Disiplin Kerja memiliki pengaruh positif; 3) Kompetensi terhadap pelaksanaan K3 memiliki pengaruh positif, 4) komitmen karyawan terhadap pelaksanaan K3 memiliki pengaruh positif, dan 5) komitmen karyawan terhadap pelaksanaan K3 melalui disiplin kerja memiliki pengaruh.

\section{PEMBAHASAN}

\section{Pengaruh Komitmen Karyawan terhadap Disiplin Kerja}

Semakin tinggi tingkat komitmen karyawan maka semakin signifikan perngaruhnya terhadap disiplin kerja. Dengan komitmen karyawan yang kuat atas kesadaran menerapkan $\mathrm{K} 3$, keinginan kuat mendukung budaya K3 di perusahaannys serta mendukung tujuan perusahaan agar bebas dari kecelakaan kerja maka disiplin karja karyawan akan semakin baik.

Penelitian ini di dukung temuan Amalia Aqmarina Sukmawijaya (2014), bahwa variabel komitmen normatif terhadap disiplin kerja secara simultan memiliki pegaruh yang signifikan yaitu $\mathrm{F}$ hitung sebesar 31,363. Penelitian Adi Irawan (2009), hasilnya mengindikasikan bahwa komitmen organisasional yang diukur dari penerimaan dan kepercayaan karyawan pada nilai dan tujuan perusahaan, kesediaan untuk bekerja keras, keinginan kuat untuk bertahan di perusahaan, rasa memiliki perusahaan dan rasa keterlibatan dengan aktivitas perusahaan, berpengaruh positif dan signifikan terhadap disiplin karyawan. Semakin tinggi karyawan memiliki komitmen organisasional, maka tingkat kedisiplinannya juga semakin meningkat.

\section{Pengaruh Disiplin Kerja Terhadap Pelaksanaan K3}

Semakin baik disiplin kerja karyawan memberikan pengaruh yang signifikan terhadap pelaksanaan K3. Dengan disiplin kerja yang baik dapat membuat karyawan menjaga kesehatan fisiknya dengan baik, peduli dengan lingkungan sekitar kerjanya, memastikan dirinya memiliki perlindungan kesehatan, peduli dengan kondisi kerja dan udara seputar tempat kerjanya serta kondisi mental saat melakukan pekerjaan. Penelitian ini didukung oleh Putri Ismariana (2015), 
bahwa disiplin kerja berpengaruh positif terhadap kinerja karyawan.

\section{Pengaruh Komitmen karyawan Terhadap Pelaksanaan K3 melalui Disiplin Kerja}

Komitmen karyawan terhadap pelaksanaan K3 melalui disiplin kerja memberikan pengaruh yang signifikan. Karyawan yang memiliki rasa tanggung jawab terhadap aturan $\mathrm{K} 3$, disiplin dalam mengikuti meeting terkait K3 serta patuh dalam menggunakan APD (alat pelindung diri) yang benar di tempat kerja menunjukan tingginya komitmen karyawan tersebut sehingga mampu memberikan pengaruh yang baik pada pelaksanaan K3.

Penelitian ini sejalan dengan penelitian Benny M.P Simanjuntak (2019), Hubungan Komitmen K3 mempunyai peluang dalam mempengaruhi Penerapan SMK3 pada divisi Utility di PT. ALMASINDO Bogor Tahun 2019, yaitu sebesar 0,208. Adapun faktor yang mempengaruhinya yakni karakteristik personal. Personal memiliki ciri-ciri kepribadian tertentu berpandangan positif (optimis), cendrung lebih komit.

\section{Pengaruh Kompetensi Karyawan Terhadap Pelaksanaan K3}

Kompetensi Karyawan dalam penelitian ini memberikan pengaruh yang signifikan terhadap pelaksanaan K3. Semakin baik karakter pribadi karyawan dalam memahami aturan dan norma K3 yang berlaku di perusahaan, mempunyai prinsip diri yang tinggi terkait $\mathrm{K} 3 \mathrm{di}$ tempat kerja, memiliki pengetahuan akan aturan kerja yang aman serta memiliki motivasi kerja yang baik maka pelaksanaan K3 di tempat kerja akan semakin baik pula.

Penelitian ini didukung oleh hasil penelitian terdahulu Chusnul Chotimah (2018) dimana semakin baik tingkat kompetensi karyawan maka akan memberikan pengaruh postif yang signifikan terhadap kinerja karyawan, sehingga kinerja karyawan yang baik akan memberikan pengaruh yang signifikan dan postif pada pelaksanaan K3.

\section{KESIMPULAN}

Pengaruh komitmen karyawan, disiplin kerja dan kompetensi karyawan terhadap pelaksanaan K3 memberikan korelasi yang positif dan pengaruh yang signifikan di perusahaan konstruksi Migas yang berada di Tanjung Balai Karimun. Semakin besar pengaruh komitmen karyawan dapat menghasilkan pengaruh yang signifikan terhadap pelaksanaan K3 melalui disiplin kerja yang baik. Semakin besar tingkat komitmen karyawan dapat memberikan pengaruh yang signifikan terhadap disiplin kerjanya serta kompetensi karyawan yang baik dapat memberikan pengaruh positif dengan pelaksanaan K3.

Perlu dilakukan penelitian lebih lanjut dengan variabel lainnya dan penelitin ini dapat dijadikan sebagai bahan referensi untuk penelitian yang akan datang.

\section{DAFTAR PUSTAKA}

Ardana, Ni Wayan Mujiati dan I Wayan Mudiartha Utama, 2012. Manajemen Sumber Daya Manusia. Yogyakarta: Graha Ilmu

Winarno, A. and Perdana, Y. 2015. 'The Effecs of Competence and Motivation on Employee Performance at PT Pos Indonesia Bandung Cilaki Head Office', Int'l Conference on Business, Marketing \& Information System Management (BMISM'15) Nov. 25-26, 2015 Paris (France), pp. 1-5. doi: doi.org/10.15242/ICEHM.ED1115030.

Chusnul Chotimah, 2018. Pengaruh Kompetensi Dan K3 (Keselamatan Dan Kesehatan Kerja) Terhadap Kinerja Karyawan Pada Pt. Lotus Indah Textile Industries Bagian Winding Di Nganju, Jurnal Ilmu Manajemen Vol 6 No 3.

Benny M.P Simanjuntak, 2019. Hubungan Komitmen K3 Dengan Penerapan Sistem Manajemenkeselamatan Dan Kesehatan Kerjapada Divisi Utillitydi Pt Almasindo Bogor, Jurnal IlmiahWijaya Vol 11 No 2. Doi: doi.org/10.46508/jiw.v11i2.58 
Putri Ismariana , Drs. Wahyu Hidayat, M.Si dan Reni Shinta Dewi, S.Sos, M.Si, 2015. Pengaruh Budaya Kerja, Disiplin Kerja Dan K3 Terhadap Kinerja Karyawan Tetap Bagian Produksi Unit Spinning 2 Pada Pt Apac Inti Corpora, Jurnal Ilmu Administrasi Bisnis Semarang: Universitas Diponegoro.

A.A Sukmawijaya, 2014. Pengaruh Komitmen Organisasi Terhadap Disiplin dan Kinerja Karyawan pada Akademi Kebidanan Ummi Khasanah Bantul Yogyakarta, Jurnal Managemen Sumber Daya Manusia Yogyakarta: Universitas Islam Indonesia

Sugiyono, 2001. Metode Penelitian, Bandung: CV Alfa Beta

Sugiyono. (2017). Metode Penelitian Kuantitatif, Kualitatif, dan R\&D. Bandung : Alfabeta, CV.

Creswell, John W. 2012. Research Design Pendekatan Kualitatif, Kuantitatif, dan Mixed. Yogyakarta: Pustaka Pelajar.

Kaynak, R. et al. 2016. 'Effects of Occupational Health and Safety Practices on Organizational Commitment, Work Alienation, and Job Performance: Using the PLS-SEM Approach', International Journal of Business and Management, 11(5), p. 146. doi: 10.5539/ijbm.v11n5p14

Dana, I. N., (2021). Pengaruh Penerapan Program K3 terhadap Perilaku Pekerja dengan Sarana \& Fasilitas Sebagai Variabel Intervening, Jurnal Syntax Transformation, 3(9). https:/ / doi.org/10.46799/jst.v2i9.411

Budiarti, A. (2019). Hubungan Pengetahuan, Pengawasan, Dan Sosialisasi Program K3 Dengan Kecelakaan Kerja Pada Pekerja Konstruksi Di Pt. Tatamulia Nusantara Indah Proyek Southgate Apartment Tanjung Barat Tahun 2019. Universitas Pembangunan Nasional Veteran Jakarta. .Google Scholar

Mohd Adzim Khalili, R., Azlina Binti, M., Norhayati, A., \& Tajul Zahili, M. (2013). Screening of seven types Terengganu herbs for their potential antibacterial activity against selected food microorganisms. Borneo Science, 9-23. .Google Scholar

Monika indrayanti Sitanggang;2019. Hubungan Antara Faktor Penghambat Dengan Pelaksanaan Sistem Manajemen Keselamatan Dan Kesehatan Kerja Di Rumah Sakit Santa Elisabeth Medan Tahun 2018, Skripsi Sumatra Utara: Universitas Sumatera Utara

Sulastini. Hidayati, Noor. Fadillah, Rozi. (2017). Pengaruh Kompetensi, Disiplin Kerja, dan Linkungan Kerja Terhadap Kinerja Karyawan pada Kantor Bank Kalsel cabang Pembantu Banjarmasin. Jurnal Bisnis dan Pembangunan, Edisi Januari-Juni, Vol 6, No. 1

Davis, K. \& Newstrom, J.W. (2002). Perilaku dalam Organisasi (terjemahan Agus Darma). Jakarta: Erlangga.

Makori, E, M., Nandi, O, M, J., Thuo, J, K., \&Wanyonyi, K, W (2012, May). Influence of Occupational Health and Safety Programmers on Performance of Manufacturing Firms in Western Province, Kenya. African Journal of Histroty and Culture (AJHC) Vol. 4 (4), pp.46-58.

Herman R. L. Siwy,2017. Persepsi Pegawai Terhadap Kesesuaian Kompensasi, Rotasi Pekerjaan Dan Kepuasan Kerja Terhadap Komitmen Organisasi Serta kinerja Pegawai, Jurnal Riset Bisnis dan Manajemen Vol 5 ,No.4, 2017: 401-418

Mowday, R. T. et al. (1983). The Measurement of Organizational Commitment. Journal of Applied Psychology. Vol.84, p. 408-414

Hasibuan, Malayu SP. (2014). Manajemen Sumber Daya Manusia, Cetakan keempatbelas, Jakarta ,Penerbit : Bumi Aksara

Manullang, Sendjun H. 2000.Pokok-pokok Hukum Ketenagakerjaan Indonesia. Jakarta: Rineka Cipta 